\title{
Influência dos aspectos silviagropecuário no desenvolvimento local de Rio Vermelho-MG
}

\author{
Luis Carlos da Silva Soares ${ }^{1}$ \\ Breno Silva da Cruz Queiroz ${ }^{2}$
}

\begin{abstract}
RESUMO
O Brasil é pais referência em produção de alimento estando dentre os três maiores produtores de alimento. Conforme o crescimento da demanda por alimentos houve a necessidade de aprimorar os meios de produção onde veio surgir a automação no campo. A grande produção leva ao barateamento de produtos e a concorrência desproporcional com setores de produção a base de pequenos produtores e agricultura familiar. As alterações levadas para o campo impactam diretamente nos setores urbanos onde levas de migrações influenciam na infraestrutura, pobreza e marginalização. Deste modo fica evidente o papel importante que o campo tem para o desenvolvimento local. Este trabalho objetivou-se analisar os impactos das atividades silvi-agropecuarias exercem na população e no meio urbano no município de Rio Vermelho - MG. Foi constatado tendência de êxodo no município o que pode ser em decorrência de atividades da silvicultura. É impossível determinar com exatidão os impactos que o ramo silviagropecuário exerce sobre o município sem realizar um estudo sistematizado de seus padrões étnicos e econômicos no quesito atividades desenvolvida em cidades uma vez que estes interferem em padrões de imigrações entra cidades. Contudo, é possível afirmar que a incrementação de culturas não anuais, ciclo de chuvas escassos contribuem fortemente para o retrocesso populacional do município ao longo de décadas.
\end{abstract}

Palavra chaves: Silvicultura. Agropecuária. Desenvolvimento rural.

\section{Influence of silvi-agricultural aspects On the local development of Rio Vermelho-MG}

\begin{abstract}
Brazil is a reference country in food production, being among the three largest food producers. As the demand for food grew, there was a need to improve the means of production where automation in the field emerged. Large production leads to cheaper products and disproportionate competition with production sectors based on small producers and family farming. The changes taken to the countryside have a direct impact on urban sectors where waves of migration influence infrastructure, poverty and marginalization. In this way, the field plays an important role in local development. This work aimed to analyze the impacts of silvi-agricultural activities on the population and the urban environment in the municipality of Rio Vermelho - MG. There was a trend of exodus in the municipality, which may be due to forestry activities. It is impossible to accurately determine the impacts that the silviagropecuário branch exerts on the municipality without conducting a systematic study of its ethnic and economic patterns in terms of activities developed in cities, since these interfere in immigration patterns between cities. However, it is possible to affirm that the increase in non-annual crops, a scarce rain cycle, contributes strongly to the population's decline in the municipality over decades.
\end{abstract}

Keywords: Silviculture. Agriculture. Rural development.

\section{INTRODUÇÃO}

O Brasil é um dos países que mais cresceram nas últimas décadas destacando-se pela sua participação na economia mundial com um produto interno bruto formado principalmente

\footnotetext{
${ }^{1}$ Eng. Florestal. Instituto Federal de Minas Gerais (IFMG). Tutor nas disciplinas de Química Orgânica, Química Analítica e Genética. Possui experiencia nos SIGs QGIS, ENVI e SPRING. Email luisccbvgp@ gmail.com

2 Téc. em Mineração (IESMIG). Eng. Florestal. Instituto Federal de Minas Gerais (IFMG), Campus São João Evangelista, MG. Atuou como Professor de Ciências e Biologia. Atualmente Professor de Química.
} 
pela agricultura, pecuária e extrativismo vegetal e mineral. O país é um grande exportador de insumos agropecuários tornando-o o terceiro pais que mais vende alimentos do mundo. Contudo, o panorama prescrito trata-se de uma agricultura mecanizada a qual não tem participação considerável de produtos de agricultura familiar (COSTA et.al, 2015).

A produção agrícola de ramo industrial surgiu como a necessidade de suprir a demanda aparente de alimentos que a população necessitava. O Brasil desde sua colonização até o período pós-guerra recebia significante quantidade de imigrantes oriundos de todo o mundo. Com o fim da segunda guerra mundial e com o avanço na área de pesquisas farmacêuticas, após 1960, a taxa de natalidade no Brasil e no mundo cresceu de maneira significante. Deste modo, o modelo de produção agropecuário da época não conseguiria atender toda a demanda da população. Surge então modelos de produções agropecuários mais eficientes para uma produção maciça que atendesse a demanda emergente (CARVALHO, 1995).

Alimentar a crescente população mundial de forma sustentável é um desafio real e imediato de países com vocação para produção, como o Brasil. O número de pessoas atingidas pela fome em nível mundial diminuiu em mais de 100 milhões na última década, mas há ainda cerca de 805 milhões de pessoas não têm comida suficiente para levar uma vida saudável e ativa, segundo a FAO (2015). Ainda, de acordo com estimativas da organização, o Brasil precisará aumentar sua produção em 40\% para suprir a demanda mundial em 2050.

A produção de ramo industrial vem a gerar grandes quantidades de insumos a preços mais baixos que produtos manufaturados. De forma análoga, a mecanização agrícola produz alimentos mais rápidos e baratos do que os produtores rurais. Consequentemente, essa alteração no cenário de mercado afere diretamente aos produtores rurais bem como o desenvolvimento local, reduzindo postos de trabalho no campo (BALSADI, 2001).

\section{REVISÃO}

\subsection{Desenvolvimento Local}

O termo desenvolvimento local é uma expressão de significado amplo e incerto. Em linhas diretas o desenvolvimento é descrito por Muls (2008) como "o resultado da falência dos modelos tradicionais de desenvolvimento fundados seja na compreensão do Estado nacional, seja nas funções alocativas do mercado como facilitador do ótimo econômico".

O desenvolvimento local não é intrínseco unicamente ao crescimento econômico de uma dada região. Tal conceito é correlato da melhoria de vida da população de dada área ao passo

Revista Desenvolvimento Socioeconômico em debate v.6 n.2 (2020) 
que há a preocupação com questões ambientais. Para Veiga 2000, o fator econômico é o fator dominante, uma vez que graças a ele é possível gerar o melhoramento no padrão de vida social se considerarmos que o padrão ambiental é inerente ao social.

Para SACHS (2001),

O desenvolvimento local pressupõe uma transformação consciente da realidade local. Isto implica em uma preocupação não apenas com a geração presente, mas também com as gerações futuras e é neste aspecto que o fator ambiental assume fundamental importância. O desgaste ambiental pode não interferir diretamente a geração atual, mas pode comprometer sobremaneira as próximas gerações SACHS (2001),

Os mecanismos de desenvolvimento ou arranjo local no ato de superação de desafio imposto pelo mecanismo de globalização e pela alta competitividade nos mercados atuais vem aferidos pela influência de formuladores de políticas públicas (TABOSA et.al 2004). A superação desses desafios impostos é intrínseca às micro e pequenas empresas os quais imperializam os núcleos urbanos atraindo por sua vez investimento local na infraestrutura urbana e na geração de empregos (AMARAL, 2002).

\subsection{Desenvolvimento Rural}

O desenvolvimento rural é entendido como a criação de meios os quais permitem as populações rurais transformarem a condição de vida das mesmas. Para tanto é indispensável que haja um estreitamento entre tal população com o Estado (CONGRAF, 2013). Contudo, o desenvolvimento rural não existe como um fenômeno independente do desenvolvimento urbano (VEIGA,2000). Para Veiga (2000) "o desenvolvimento é um processo complexo, por isso, muitas vezes se recorre ao recurso mental de simplificação, estudando separadamente o desenvolvimento econômico".

Em 2014, as Nações Unidas determinaram como tema principal para debates o papel dos pequenos agricultores no desenvolvimento rural. Tanto em países em desenvolvimento, como em nações desenvolvidas, a agricultura familiar é a forma predominante de agricultura na produção de alimentos. Atualmente cerca de $70 \%$ dos alimentos que chegam às nossas mesas são provenientes das mãos dos pequenos agricultores. Sendo assim, o setor carrega um importante pilar da agricultura mundial (FAO, 2017).

O desenvolvimento rural tem como finalidade criar transformações em direções desejáveis em meios rurais usando diversos mecanismos para a obtenção do resultado. De forma geral, o desenvolvimento rural recai sobre a necessidade de criação de produtos e serviços associados a um mercado. Tal projeto pleiteia a redução de custos aplicando meios tecnológicos 
tentando reconstruir a agricultura da economia rural derrubando o paradigma e limitações criadas pela modernização que a indústria impõe (PLOEG, 2000).

Entretanto, o desenvolvimento rural é munido de um conjunto de limites que impede o avanço ou sua real eficácia o que vem a tornar a implementação das mudanças no meio rural um processo complexo e pouco eficaz.

Para NAVARRO (2001),

\begin{abstract}
Atualmente há um conjunto de limites que, se secundarizados, provavelmente condenariam ex-ante qualquer iniciativa no sentido do desenvolvimento rural.[...]. A abertura comercial e o acirramento concorrencial derivado da globalização têm significado, de fato, um gradual "encurralamento" das opções que se apresentam ao mundo rural. Como resultado, o poder de manobra dos Estados nacionais para erigir programas de desenvolvimento rural que mantenham alguma autonomia própria tem sido igualmente reduzido com o passar dos anos (NAVARRO, 2001).
\end{abstract}

A limitação do desenvolvimento rural no Brasil gera problemas que afeta diretamente as populações rurais as quais estão intrínsecas as mesma e indiretamente os grandes centros urbanos. O resultado dessa limitação tende a gerar o fenômeno do Êxodo rural o qual fragiliza o equilíbrio do desenvolvimento Rural ao Desenvolvimento Urbano (FONSCECA et.al,2015).

\title{
2.3 Êxodo Rural
}

O êxodo rural não é um fenômeno populacional que teve origem na atualidade. Tal fenômeno, caracterizado pela translocação de pessoas do meio rural para centros urbanos, teve suas raízes na antiguidade com acentuação no século XVIII durante o período da Revolução industrial (MARTINS 2013).

O Fenômeno do êxodo rural no Brasil foi muito fraco até a última metade do século passado onde, na política de Juscelino Kubitschek, iniciou um processo acentuado de industrialização e desenvolvimento nacional. Contudo, o setor agropecuário foi negligenciado inicialmente, faltando investimento para o mesmo. Anos mais tarde, de forma antagônica, os produtores rurais receberam incentivo fiscal, contudo grandes produtores se beneficiaram mais das políticas dos incentivos fiscais quando comparada a pequenas propriedades, aumentando a desigualdade entre eles, o que coacta como um dos principais fatores de expulsão do meio rural (CAMARANO; ABRAMOVAY, 1998).

O desencadeamento do êxodo rural é uma modalidade de migração em consequência, entre outros fatores, da implantação de um modelo econômico moderno na produção agropecuária, onde afetou profundamente a vida dos agricultores familiares A modernização da agricultura incentivou a mecanização do setor rural, porém, a adoção do novo modelo padrão tecnológico, baseado em insumos agrícolas e na mecanização, quebrou a lógica da agricultura familiar uma vez que os produtores de 
baixa que não conseguem realizar mecanização em sua produção e têm baixo rendimento de produtividade, está submetido à desvantagem no mercado. (FONSCECA et.al,2014).

O processo de êxodo pode gerar problemas graves nas cidades variando conforme a infraestrutura do mesmo. A chegada de uma massa humana não esperada em meio não preparado gera desemprego e subemprego, além de problemas sociais, aumento de favelas e superpovoamento de áreas sem estrutura, o que corrobora com o abaixamento do Índice de Desenvolvimento Humano. (LOPES, 2002).

Na tentativa de reduzir os efeitos adversos que o êxodo rural traz à meios urbanos é necessário que haja incentivo fiscal para subsidiar produtores rurais freando a massa migratória. Outra forma para reverter esse quadro seria a reforma agraria (LOPES,2002).

Com a ampliação da fome e da miséria, do desemprego, do inchaço dos centros urbanos e das reduzidas taxas de crescimento econômico, os assentamentos rurais representam uma importante iniciativa no sentido de gerar empregos diretos e indiretos a baixo custo e para estabelecer um modelo de desenvolvimento agrícola em bases sociais mais igualitárias (FONSCECA et.al,2015).

Entretanto, a reforma Agrária no Brasil torna-se distante do ideal. Segundo os dados fornecidos pelo INCRA, um número massivo de famílias já assentadas perece de infraestrutura básica para desenvolverem suas atividades no campo. A falta de seletividade na escolha para a distribuição de terra, seja por falta de capacitação de pessoas para realizar o trabalho campestre ou pela ganância humana, fortalece o desvio da prerrogativa da reforma agrária levando ao um mal uso das terras doadas (FARIAS, 2013)

Diante de tais expostos tal trabalho objetivou-se em analisar o desenvolvimento local do município de Rio Vermelho - MG baseando-se nas atividades Silvi-agropecuarias desenvolvidas por esse.

\section{MÉTODO}

A região de estudo corresponde ao município de Rio Vermelho-MG situado nas coordenadas $18^{\circ} 17^{\prime} 38^{\prime \prime} \mathrm{S} 43^{\circ} 0^{\prime} 32^{\prime \prime} \mathrm{O}$, cuja a área é de $987 \mathrm{~km}^{2}$ e densidade demográfica de 13,8 habitantes por $\mathrm{km}^{2}$.

O delineamento do estudo de tal trabalho refere-se à uma análise do comportamento do município frente as atividades Silvi-agropecuárias. Para este trabalho foram realizadas coletas de informações juntamente ao IBGE e ao SEBRAE acerca da produção agropecuária e silvicultural do município, juntamente com índices de desenvolvimento humano, produto 
interno bruto, número de habitantes na região, saneamento, escolaridade, localização dos domicílios e população economicamente ativa.

Os dados coletados foram analisados de forma sucinta por intermédio de separação destes em tabelas individuais. Foram construídos gráficos das informações relevantes para poder facilitar a análise dos dados de interesse. As informações relevantes foram correlacionadas a fim de averiguar o comportamento de tal setor frente à um ou mais fatores quando este houver variação.

\section{RESULTADOS E DISCUSSÃO}

Segundo dados do Serviço Brasileiro de Apoio às Micro e Pequenas Empresas (SEBRAE) e do Instituto Brasileiro de Geografia e Estatística (IBGE), o município de Rio Vermelho contou com uma população estimada em 2016 de 13.523 habitantes uma queda de 0,89\% da população de 2010, ficando acima da média do período de 1971 à 2010, o qual a taxa média foi de $0,6 \%$, indicando intensificação do êxodo de pessoas para outras regiões.

Figura 1. Características da população de Rio Vermelho entre os anos de 1971 a 2010

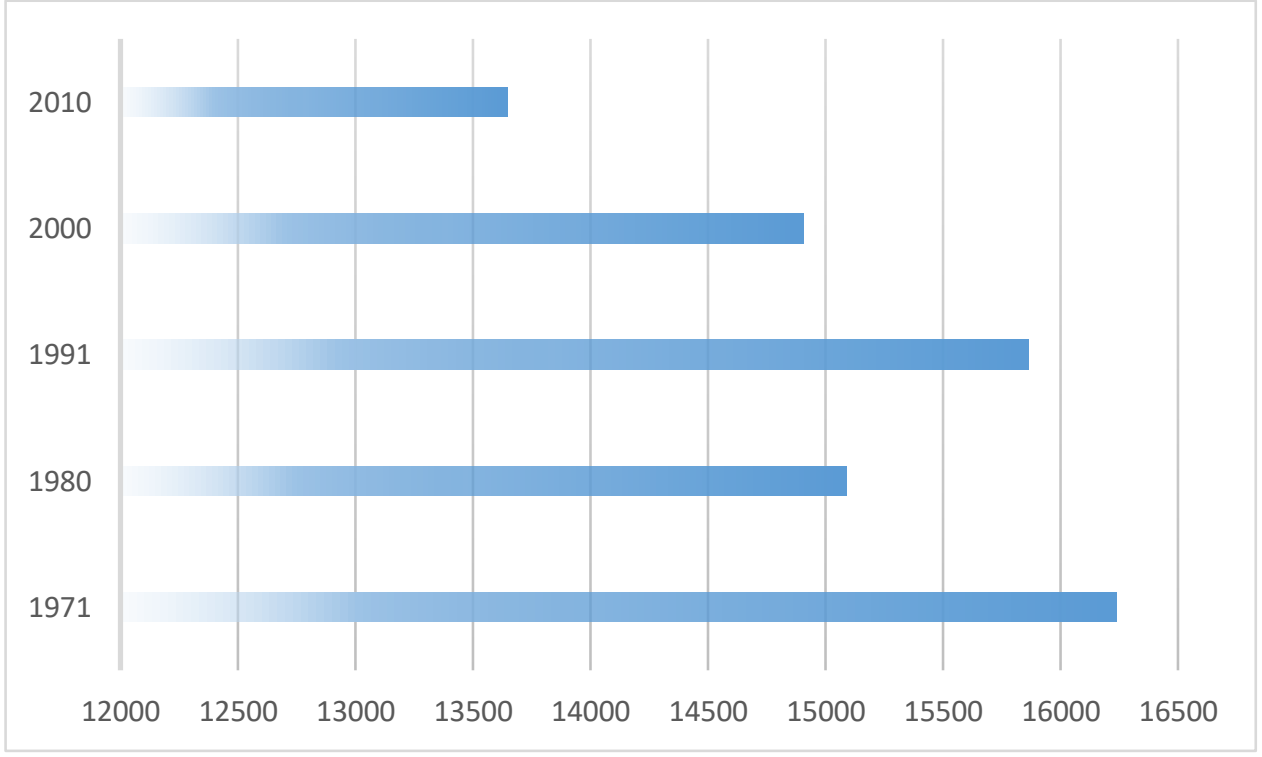

Fonte: SEBRAE, 2017.

De 2000 para 2010 observa-se um incremento de domicílios no município e uma alteração na proporção de residências entre as zonas urbanas e rurais. Conforme observa-se na figura 2, houve um aumento de $8 \%$ de domicílios na zona urbana entre o período o que pode indicar maior taxa de êxodo rural ou um inchaço urbano. 
Figura 2. Situação dos domicílios do município de Rio Vermelho dos anos de 2000 e 2010
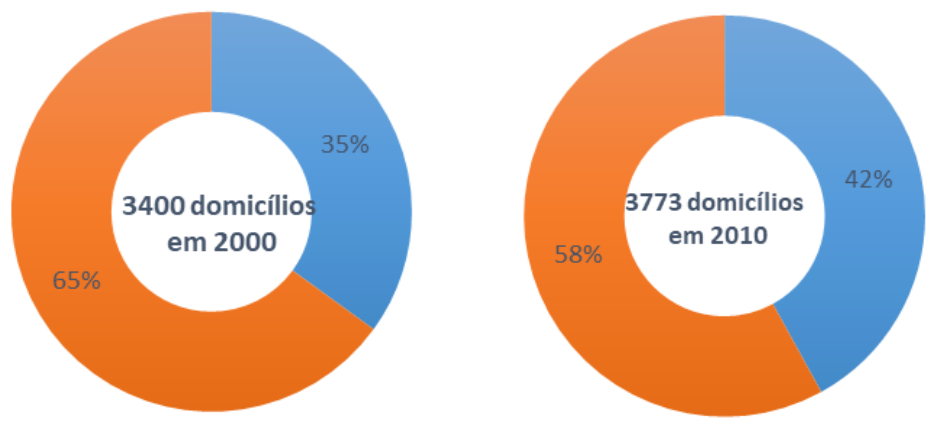

Fonte. SEBRAE, 2017

\subsection{Da Economia Rural}

Ao se analisar economia Rural do Município apresentada pela figura 3 observa-se incremento do mesmo no ano de 2013 em relação a 2010, o qual corresponde a um aumento de $11 \%$ justificado pelo aumento da produção agrícola (tabela 2), de bovinos e frango (tabela 3) e consequentemente valor do leite (figura 4).

Figura 3: Aumento da participação do setor agropecuário no PIB do município de Rio Vermelho-MG.

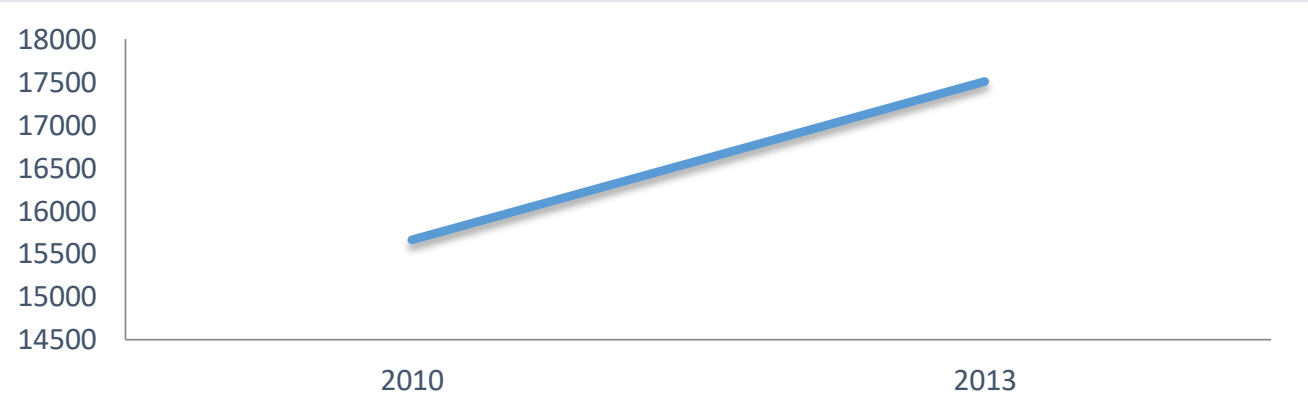

Fonte: IBGE, 2017.

A tabela 1 expressa a produção agrícola do município de rio vermelho entre o período de 2009 a 2015. Nela é possível se observar variações significantes em cada insumo a partir de 2013 com queda continua da banana, o qual era o principal produto agronômico do munícipio. É importante ressaltar que não há dados referentes à determinadas culturas em determinados anos o que nos leva à um leque de possibilidades de eventos que podem ter ocorrido. Após o início do declínio de produção de banana houve um aumento progressivo de insumos de café iniciado em 2012 e estagnou-se no ano subsequente. Vale ressaltar que a diminuição e extinção de produtos listados na tabela podem indicar substituição dos mesmos por outras culturas com ciclo longo. 
Tabela 1: Produção Agrícola, em toneladasdo municípios de Rio Vermelho entre 2009-2015

\begin{tabular}{cccccccc}
\hline & $\mathbf{2 0 0 9}$ & $\mathbf{2 0 1 0}$ & $\mathbf{2 0 1 1}$ & $\mathbf{2 0 1 2}$ & $\mathbf{2 0 1 3}$ & $\mathbf{2 0 1 4}$ & $\mathbf{2 0 1 5}$ \\
\hline Abacate & 9 & 9 & 9 & 9 & 8 & 8 & 8 \\
Algodão & 7 & 7 & 7 & 7 & 7 & 7 & 7 \\
Banana & 900 & 900 & 900 & 900 & 900 & 720 & 450 \\
Café & 9 & 9 & 9 & 36 & 36 & 45 & 48 \\
Goiaba & 9 & 9 & 9 & 9 & - & - & - \\
Laranja & 450 & 450 & 450 & 450 & 450 & 450 & \\
Limão & 7 & 7 & 7 & 7 & - & - & - \\
Mamão & 9 & 9 & 9 & 9 & - & & \\
Manga & 33 & 33 & - & - & - & - & - \\
Tangerina & 18 & 18 & 18 & 18 & & & \\
Urucum & 30 & 30 & 43 & 62 & 72 & 72 & 72 \\
\hline
\end{tabular}

Fonte. IBGE,2017

Embora a receita expendida de 2014 seja graças, preferencialmente, ao aumento no valor real do urucum, laranja e ao café, deve-se considerar a valor real da unidade produzida e sua variação. A banana obteve uma queda na sua produção o que resultou em uma menor arrecadação monetária ao ano. Contudo, em relação à 2013 o valor monetário da produção obteve um aumento de $10 \%$ por tonelada produzida. As culturas de café, laranja e urucum por sua vez em relação ao mesmo período obtiveram aumento monetário respectivamente de cerca de $24 \%, 0,42 \%$ e $7,5 \%$.

$\mathrm{O}$ aumento dos preços por toneladas pode vir a ocorrer por dois principais fatores. $\mathrm{O}$ primeiro dele pode estar ligado à recessão econômica o que eleva a taxa SELIC implicando no aumento do IPCA. Outro fator pode ser a é balança comercial favorável a qual, por sua vez, força os valores dos produtos variarem inversamente ao número de produtos disponíveis para o consumo.

Tabela 2 - Valores, em 1000 reais, do total produzido da agricultura entre 2009-2015

\begin{tabular}{cccccccc}
\hline Insumos & $\mathbf{2 0 0 9}$ & $\mathbf{2 0 1 0}$ & $\mathbf{2 0 1 1}$ & $\mathbf{2 0 1 2}$ & $\mathbf{2 0 1 3}$ & $\mathbf{2 0 1 4}$ & $\mathbf{2 0 1 5}$ \\
\hline Abacate & 6 & 5 & 5 & 6 & 6 & 6 & 6 \\
Algodão & 4 & 4 & 4 & 4 & 4 & 4 & 4 \\
Banana & 567 & 567 & 603 & 630 & 810 & 720 & 450 \\
Café & 34 & 34 & 45 & 216 & 144 & 270 & 312 \\
Goiaba & 2 & 9 & 10 & 0 & - & - & - \\
Laranja & 450 & 225 & 225 & 225 & 270 & 315 & - \\
Limão & 5 & 4 & 4 & 4 & - & - & - \\
Mamão & 6 & 6 & 6 & 9 & - & - & - \\
Manga & 8 & 8 & 14 & 17 & - & - & - \\
Tangerina & 14 & 16 & 16 & 9 & - & - & - \\
Urucum & 39 & 60 & 86 & 155 & 180 & 216 & 216 \\
Total & 1135 & 938 & 1018 & 1275 & 1414 & 1531 & 988 \\
\hline
\end{tabular}

Fonte: IBGE, 2017 
É incerto poder afirmar qualquer assertiva, mas um fator que é inerente a tal fato é a condição climática e disponibilidade de chuva de uma região o que alimenta a balança as flutuações na balança comercial favorável.

Os anos de 2010 e 2015 possuem a menor arrecadação monetária de produção bruta do período analisado. Em análise rápida, observa-se que o declínio da arrecadação de 2010 é referente principalmente à desvalorização do preço da laranja, o qual teve uma recessão de 50\% em relação ao mesmo período do ano anterior, proporcionando um rombo de cerca de $\mathrm{R} \$$ 225.000,00. O ano de 2015 apresenta um padrão não muito distinto em relação à 2010. Segundo os dados apurado do IBGE, em 2015 não se teve conhecimento de produção de Laranjas o que já contribui fortemente à queda do rendimento rural. Outro fator que coacta é a diminuição de produção de banana o que corrobora para declinar o valor bruto arrecadado.

Por se tratar de um município de caráter rural, com maioria das residências alocadas em perímetro rural, é importante fazer o estudo dos dados da pecuária para determinar o comportamento do município e das alterações na agricultura e/ou silvicultura.

O município conta como principais produtos da pecuária a manada de bovinos, criação de suínos e frangos. Acerca do primeiro item analisa-se o crescimento gradual da produção do período de 2009 a 2013, com taxa de crescimento anual de cerca de 5,14\%. Posterior a tal período inicia-se uma queda não regular em 2014 cujo ápice foi atingido em 2015, período este cujo detém menor produção ficando abaixo da média do período.

A produção de frangos segue a prerrogativa acerca dos bovinos, com pequena variação em 2012 onde há uma queda de 0,38\%. Assim como nos bovinos, a queda real começa a ser notada em 2014, contudo, neste ano, a produção ficou abaixo da média do período de 2009 a 2015, sendo este recuperado em 2015, onde deteve a segunda maior produção do período.

A criação de equinos e suínos contém números de cabeças menores que as criações já citadas. Contudo, o comportamento destas merece atenção como as demais. Ambas possuem crescimento real até 2012. A partir de tal período há declínio da criação e estagnação até 2014 para equinos e uma variação não linear para suínos. Por fim analisa-se que em 2015 ambas as criações declinam-se obtendo os menores valores do período ficando, inclusive, abaixo da média.

As demais criações de animais não citadas, mas que estão inclusas na tabela abaixo, detém um comportamento similar para ambas. Bubalinos, Caprinos e Ovinos detém um valor maior, em 2015, que a média do período, sendo que estes obtiveram um crescimento real após 2012. 
Tabela 3- Total de cabeças do setor da pecuária dentre o período de 2009-2015

\begin{tabular}{cccccccccc}
\hline ANOS & Bovinos & Equinos & Bubalinos & Asininos & Muares & Suínos & Caprinos & Ovinos & Frangos \\
\hline $\mathbf{2 0 0 9}$ & 27700 & 690 & 0 & 11 & 630 & 5600 & 48 & 40 & 25500 \\
$\mathbf{2 0 1 0}$ & 28915 & 700 & 0 & 12 & 640 & 5655 & 50 & 42 & 26100 \\
$\mathbf{2 0 1 1}$ & 30000 & 800 & 105 & 10 & 650 & 5660 & 40 & 35 & 26100 \\
$\mathbf{2 0 1 2}$ & 30600 & 1020 & 103 & 10 & 400 & 4900 & 30 & 25 & 26000 \\
$\mathbf{2 0 1 3}$ & 33786 & 950 & 73 & 0 & 0 & 3520 & 30 & 25 & 36500 \\
$\mathbf{2 0 1 4}$ & 33296 & 950 & 73 & 0 & 0 & 3620 & 30 & 25 & 24000 \\
$\mathbf{2 0 1 5}$ & 20.004 & 680 & 93 & 10 & 600 & 2900 & 47 & 38 & 27000 \\
Total & 204301 & 5790 & 447 & 53 & 2920 & 31845 & 275 & 230 & 191200 \\
Média & 23.852 & 685 & 47 & 11 & 615 & 4.250 & 48 & 39 & 26.250 \\
\hline Fonte: IBGE, 2017 & & & & & & & &
\end{tabular}

A produção de leite de 2011 a 2015 conforme visto na figura 4 tem um comportamento anômalo ao se comparar com a quantidade de bovinos totais. Conforme disposto na tabela, os bovinos tiveram um crescimento real até 2013. De forma proporcional e conforme demonstrado na figura 4 os preços crescem à medida que a quantidade cresce. De forma análoga, o declínio do número de cabeças em 2014 é acompanhado com o declínio no preço de leite. Contudo, em 2015, há um declínio de números de cabeça em comparação ao ano anterior, contudo, o preço do leite não variou diretamente ao comportamento do declínio e sim inversamente. Pela escassez de dados é improvável ter uma conclusão sobre tal comportamento, contudo o mais provável pode ser um aumento real de vacas leiteiras dentro do grupo dos bovinos o que pode a vir provoca um aumento da produção de leite. Outra acertiva viável seria a melhoria da pastagem para as vacas o que condiciona uma melhor nutrição dos boninos o que vem a converter numa melhor produtividade de leite.

Figura 4: Valor, em R\$, de leite produzido no município de Rio Vermelho entre 2009-2015

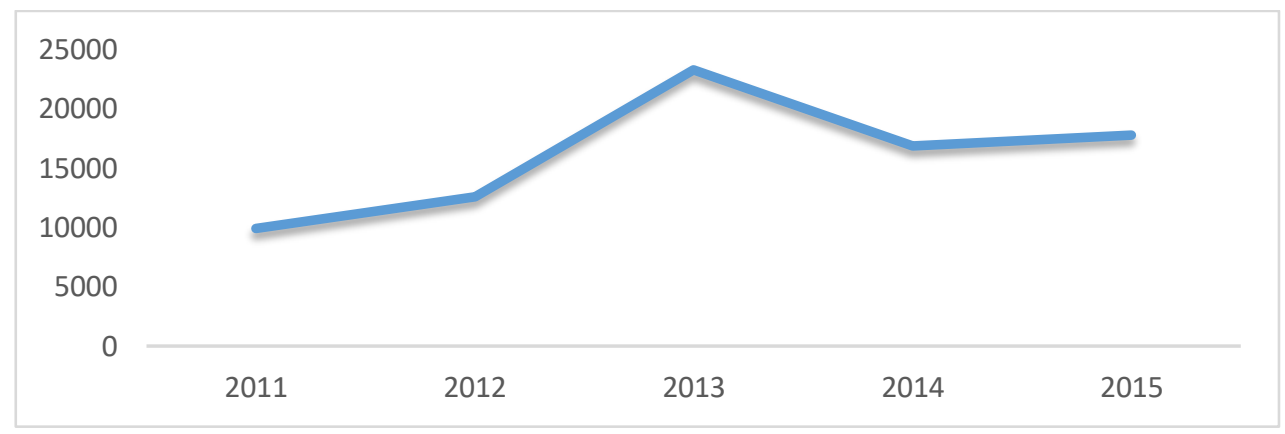

Fonte: IBGE, 2017

Outro ramo principal do setor do campo que merece destaque no município de Rio Vermelho-MG é o setor da silvicultura. Verifica-se através dos dados coletados que os 
principais produtos de tal setor é o carvão vegetal, a lenha e a Madeira em tora e para outras finalidades.

Ao decorrer dos anos verifica-se instabilidades nas variações numéricas de quantidade produzidas de cada insumo silvicultural o que implica diretamente no valor arrecado de cada ano. Verifica-se, primeiramente, a diminuição gradativa da lenha até 2011 . A queda de 99,25\% na produção de lenha de reservas florestais, entretanto, vem a ser compensada pelo aumento de $17.000 \%$ da produção de madeira em tora em 2011 em relação à 2010. Contudo, a soma dos valores brutos até de 2011 delineia uma queda de 23,08\% algo em torno de $\mathrm{R} \$ 211.000$.

A partir de 2012 o cenário dos principais produtos silviculturas ficam análogos em relação aos anos anteriores. Verifica-se um aumento aproximadamente de 9 vezes na produção carvoeira do período 2012-2014 em relação à 2009-2011. Tal insumo movimentou dentro do período de 2012-2015 cerca de $\mathrm{R} \$ 1.820 .000,00$ reais o que representa cerca de 99,5\% da totalidade de valor bruto produzido.

A destinação do carvão produzido em Rio Vermelho é incerta, contudo, provavelmente parte da produção é convertida em produtos para abastecimento comercial local. Outra parte, a majoritária, é destinada à abastecimento de siderurgias dentro do vale do aço.

Tabela 4 - Valores produzidos de insumos silviculturais no município de Rio Vermelho no período de 2009-2015.

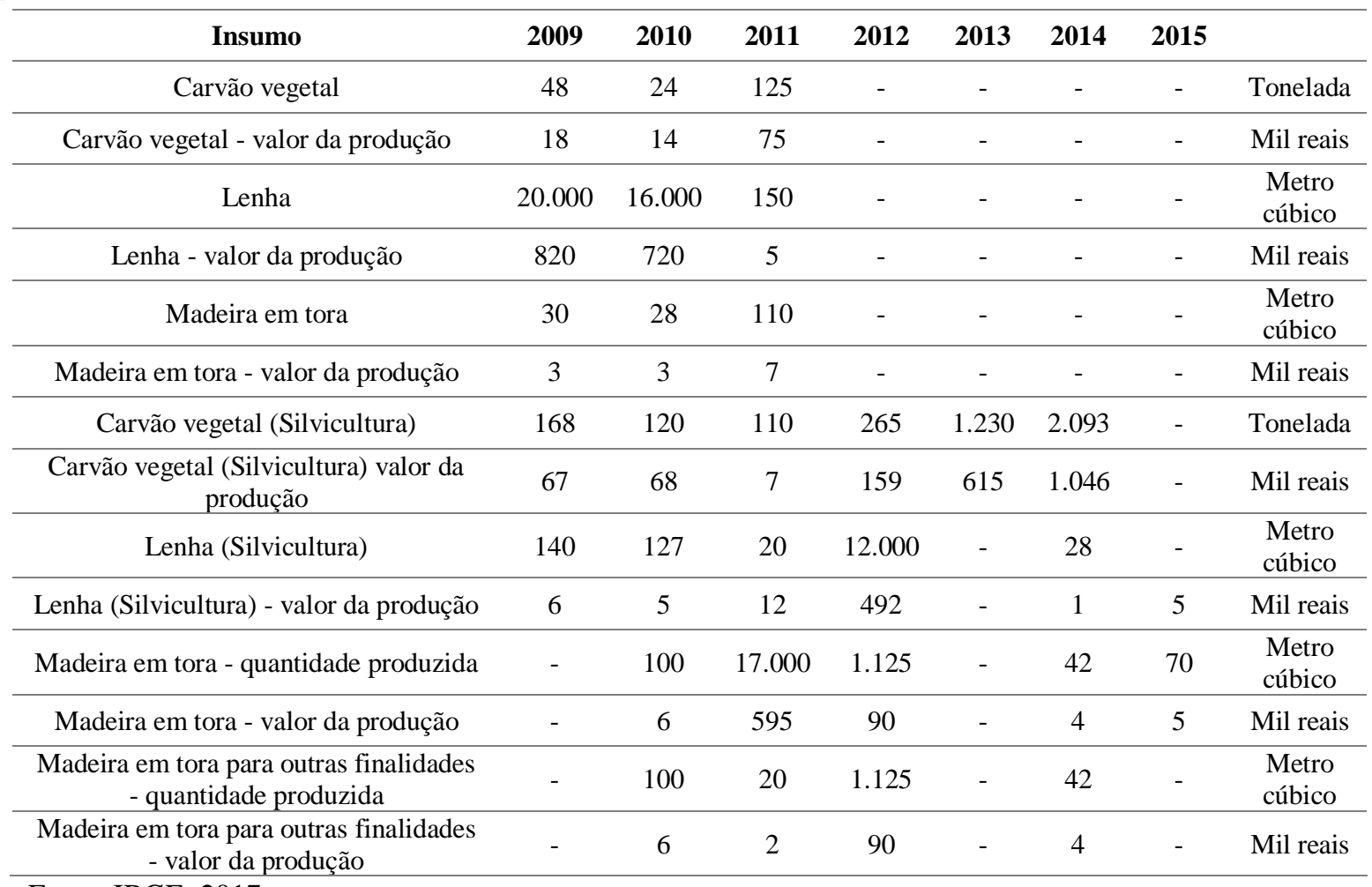

Fonte: IBGE, 2017 
A tabela de insumos silviculturais apresenta lacunas onde é representada pelo símbolo “(-)" que representa o desconhecimento de produção de certo insumo naquele ano. Na tabela 4 verifica-se o desaparecimento de insumos o que pode facilmente ser explicado. Em se tratando de produtos silviculturais deve se levar em consideração o tempo em relação ao plantio e à colheita, o que fica em torno de 7 anos. Assim, possivelmente, o desaparecimento de insumos coletados em algum ano, ou o desaparecimento total, bem como sua redução pode estar relacionada diretamente a este fator.

Outro ponto importante, quando se trata de produtores de madeiras individuais, é a normalidade que estes deixem suas plantações florestais intactas, caso o preço dos produtos no mercado não os convir. De tal maneira esperam que o mercado aqueça para que façam a colheita o que pode corroborar com aumento de lucros.

O ramo da Silviagropecuária exerce influência nas modificações de contingentes urbanos do município de Rio Vermelho. Como visto na tabela anterior, notasse um aumento considerável na expansão do setor de silvicultura a qual demanda um espaço considerável de terra. Tal fator pode corroborar para o êxodo rural, uma vez que os produtores vêm a ceder suas terras para uma monocultura de eucalipto. A ausência de monoculturas agrícolas, como demonstrado na tabela 2, corrobora com o aumento do eucalipto nesta área, onde há a expansão de um setor em detrimento de outro.

Conforme apresentado na figura 1 existe a tendência da diminuição da população ao longo da história. Um fator que pode estar intrínseco, além da diminuição da taxa de natalidade, é à essa taxa de evasão é o crescimento da monocultura de eucalipto. Como mencionado anteriormente, os produtores rurais tendem a ser aventurar nas cidades em busca de uma nova vida. Contudo, este cenário corrobora com um inchaço urbano à um município de caráter rural. De tal forma, por falta de infraestrutura e condições de vida e por falta de capacitação, as pessoas tendem a sair para grandes centros em busca de estabilidade.

Em 2010, segundo os dados fornecidos pelo SEBRAE, a taxa da população economicamente ativa ficava em torno de $50 \%$, enquanto a não ativa também ficava em torno de $50 \%$. No mesmo período o município contava com cerca de $80 \%$ de pessoas sem instrução o que pode estar correlacionado fortemente à população do campo. Como as atividades urbanas necessitam, em partes, certo grau de instrução é previsto que à população instruída desempenha mais atividades no setor urbano em detrimento das não instruídas. 
Figura 5 - Porcentagens da População Economicamente Ativa e inativade Rio Vermelho - MG

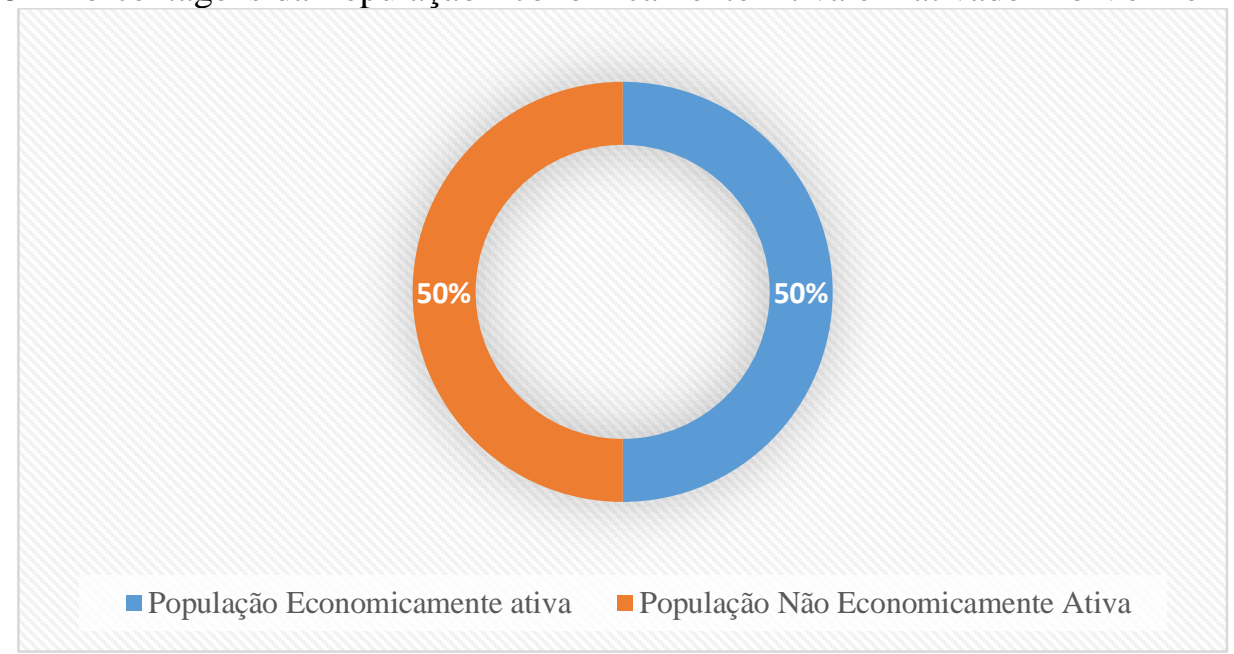

Fonte. SEBRAE, População, 2010

Figura 6: Escolaridade da população adulta do município de Rio Vermelho - MG

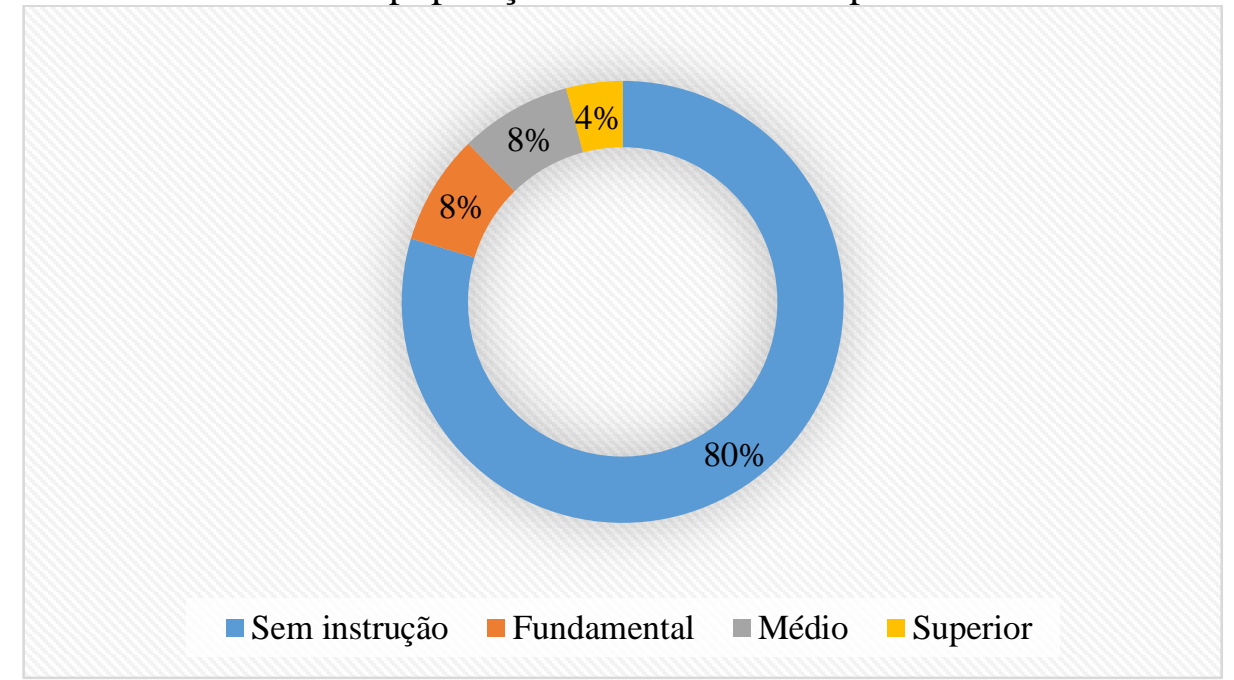

Fonte: IBGE (2017)

Com o crescente êxodo rural que se verifica no município observa-se certa relação com o grau de instrução bem como o grau de escolaridade da mesma. Como a maioria das pessoas oriundas carecem de certo grau de instrução e há a necessidade de mão de obra especializada nas cidades, grande parte do contingente do êxodo rural tendem a migrar para outras regiões intensificando a diminuição da população total do município.

\subsection{Produto Interno Bruto}

O município de Rio Vermelho - MG tem uma economia aparente de caráter rural. Contudo, a produção de insumo rural de tal município corrobora com menos de $50 \%$ do PIB do mesmo segundo dados do SEBRAE. Sua produção rural tem como principal função suprir a 
demanda interna do mesmo, seja atender o comercio ou as famílias campestres. A produção agropecuária cresceu, contribuindo para o aumento da renda bruta do município.

A produção Rural de Rio Vermelho tem um caráter análogo ao crescimento do PIB da união. Enquanto o PIB da União cresce, a produção rural diminui em relação ao mesmo. Contudo, vale ressaltar que o inverso também acontece, ou seja, à medida que o PIB diminui, a produção rural do município aumenta conforme é demonstrado na figura 7.

Figura 7- Comportamento da Agropecuária Frente ao PIB nacional \%

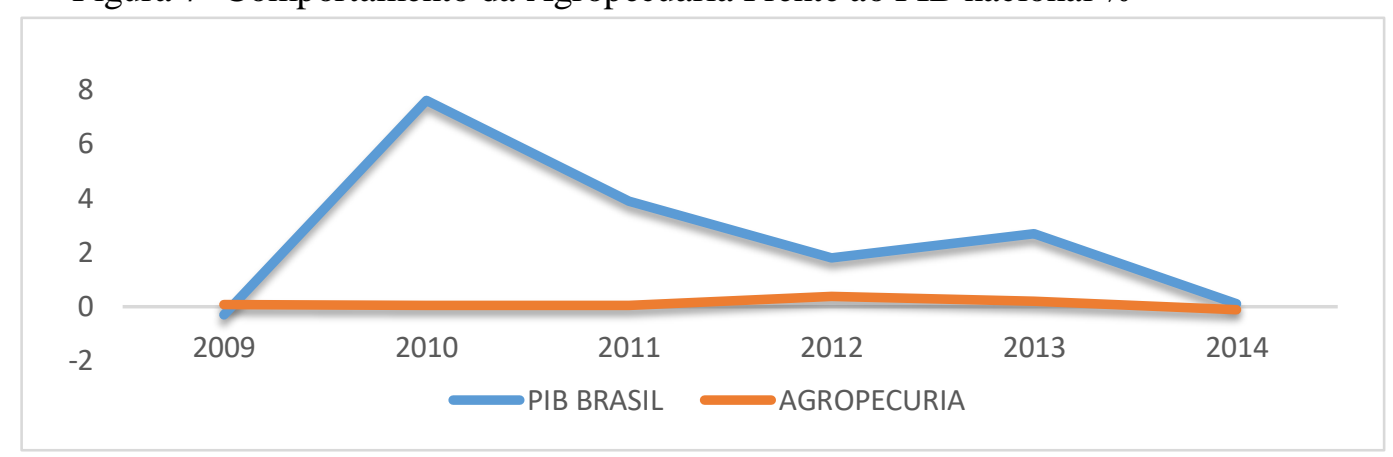

Fonte: IBGE,2017

Esse comportamento é explicado pelo aumento da procura de produtos rurais do mercado interno devido ao aumento no preço de produtos de agricultura no setor industrial. Com a queda do PIB há o aumento da taxa SELIC e, consequentemente, aumento da inflação e do IPCA. Com a desvalorização da moeda e o aumento do IPCA, os moradores recorrem à produtos do setor agro familiar afim de contornar a situação de risco financeiro na qual estas se encontram.

\section{CONSIDERAÇÕES FINAIS}

É visível o impacto que as atividades do setor silvi-agropecuarios exercem sobre o município de Rio Vermelho. Notoriamente a expansão do setor da Silvicultura, de forma aparente, exerce função de retenção da expansão de certas monoculturas agrícolas. O setor silvicultural tem menos gasto de conservação e de mão de obra o que corrobora para sua intensificação nos últimos anos. Tal expansão caracteriza uma perda da mão de obra do campo, uma vez que as monoculturas agrícolas necessitam de constantes mão de obras uma vez que estas são perenes.

A silvicultura pode estar influenciando o êxodo rural devido pela perda do trabalho por parte de substituição de culturas. Assim há a migração do homem do campo para cidades ou outras localidades. 
Com a queda dos principais produtos e pela incapacidade de retomada de produção dos mesmos, o impacto no PIB no setor agropecuário é eminente. A partir de 2014, o PIB agropecuário do município que estava em crescimento teve retrocesso de $11 \%$ em relação ao ano anterior. Em se tratando de um município de caráter rural isso gera grandes impactos à população. Entretanto, ao se comparar a variação do PIB agropecuário dos outros anos em relação ao PIB nacional verifica-se padrões inversos de ordem de crescimento onde é verificado um maior desenvolvimento da produção interna do município. Em termos econômicos isso significa que há um aumento no consumo dos produtos internos em detrimento dos produtos oriundos de grandes plantações, o que fomenta o comercio local da região.

É impossível determinar com exatidão os impactos que o ramo silviagropecuário exerce sobre o município sem realizar um estudo sistematizado de seus padrões étnicos e econômicos no quesito atividades desenvolvida em cidades uma vez que estes interferem em padrões de imigrações entra cidades. Contudo, é possível afirmar que a incrementação de culturas não anuais, ciclo de chuvas escassos contribuem fortemente para o retrocesso populacional do município ao longo de décadas.

\section{REFERÊNCIAS}

AMARALFILHO, Jair do. Núcleos e Arranjos Produtivos Locais: casos do Ceará. VII Encontro Regional de Economia BNB/ANPEC, Fortaleza.2002

BALSADI, Otavio Valentim. Mudanças no meio rural e desafios para o desenvolvimento sustentável. São Paulo Perspec., São Paulo, v. 15, n. 1, p. 155-165, Jan. 2001

BARBOSA, G.S: O Desafio Do Desenvolvimento Sustentável. Revista Visões $4^{\text {a }}$ Edição. Volume 1 Rio de Janeiro. Revista Visões. Jan/Jun 2008.

Camarano, A. A.; Abramovay, R. Êxodo rural, envelhecimento e masculinização no

Brasil: panorama dos últimos cinquenta anos.Revista Brasileira de Estudos de População, Rio de Janeiro: Associação Brasileira de Estudos Populacionais, v. 15, n. 2, p. 45-66, 1998.

CARVALHO FILHO, José Juliano de. A produção de alimentos e o problema da segurança alimentar. Estud. av., São Paulo, v. 9, n. 24, p. 173-193, Aug. 1995.

CONGRAF, Meio Ambiente. Disponível em: <http://www.mma.gov.br/desenvolvimentorural>. Data de acesso: 06 de abril de 2017.

COSTA, Bianca Aparecida Lima; AMORIM JUNIOR, Paulo Cesar Gomes; SILVA, Marcio Gomes da. As Cooperativas de Agricultura Familiar e o Mercado de Compras

Governamentais em Minas Gerais. Rev. Econ. Sociol. Rural, Brasília, v. 53, n. 1, p. 109126, Mar. 2015. 
FARIAS, Marisa de Fátima Lomba. Mulheres no Movimento dos Trabalhadores Rurais Sem Terra (MST). 2013.

FONSECA et al. Causas e consequências do êxodo rural no nordeste brasileiro.

Nucleus,v.12,n.1,abr.2015

IBGE. Rio Vermelho, Minhas Gerais. Disponível em: < https://goo.gl/fZKUMk >. Acessado em 02 de maio de 2017 .

LOPES, E. S. A. A reforma agrária no brasil: um velho problema, esperando uma solução que nunca chega? Texto apresentado na Mesa Redonda "O Sentida da Reforma Agrária no Século XXI", durante o XIII Encontro Nacional de Geógrafos, realizado em João Pessoa-PB, 2002.

MATINS, C.M.P: Êxodo Rural. Disponível em

$<$ http://www.cesadufs.com.br/ORBI/public/uploadCatalago/14353018122013Geografia_Rura 1_aula_06.pdf $>$. Acessado em 27 de Abril de 2017

MULS, L.C. Desenvolvimento Local, Espaço e Território: O Conceito de Capital Social e a Importância da Formação de Redes entre Organismos e Instituições Locais. Revista Economia. Janeiro/Abril 2008

NAVARRO, Zander. Desenvolvimento rural no Brasil: os limites do passado e os caminhos do futuro. Estud. av., São Paulo, v. 15, n. 43, p. 83-100, Dec. 2001 .

PLOEG, J. D. van der et al. Rural development: from practices and policies towards theory. Sociologia Ruralis, Oxford, UK, v. 40, n. 4, p. 391-408, out. 2000.

FAO (Organização das Nações Unidas para a Agricultura e a Alimentação). (2017), Iniciativa regional da FAO aponta agricultura familiar como promotora do desenvolvimento rural sustentável e a agenda 2030. Brasil. 2017

SACHS, I. Repensando o crescimento econômico e o progresso social: o papel da política. In: ABRAMOVAY, R. et al. (Orgs.). Razões e ficções do desenvolvimento. São Paulo: Editora Unesp/Edusp, 2001.

SEBRAE - Serviço Brasileiro de Apoio às Micro e Pequenas Empresas - Características do Empreendedor. Site Disponível em:

https://www.sebraemg.com.br/atendimento/bibliotecadigital/documento/diagnostico/identidad e-dos-municipios-mineiros---rio-vermelho . Acesso em: 27 de Março de 2017

TABOSA,.M.I.O. et.al. Desenvolvimento Local E Capital Social: Uma Leitura Sobre Os Núcleos E Arranjos Produtivos Do Estado Do Ceará. Disponível em $:<$ http://www.sober.org.br/palestra/12/05P308.pdf >. Acessado em 25 de abril de 2017

VEIGA, I. P. A. Projeto Político-Pedagógico da escola: uma construção possível. 10 ed. Campinas, SP: Papirus, 2000. 